\title{
VIOLAÇÃO DOS DIREITOS HUMANOS NA AMAZÔNIA: UMA ANÁLISE DOS CASOS NA COMISSÃO INTERAMERICANA DE DIREITOS HUMANOS ENVOLVENDO POVOS TRADICIONAIS
}

\section{HUMAN RIGHTS VIOLATIONS IN THE AMAZON: AN ANALYSIS OF THE CASES IN THE INTER-AMERICAN COMMISSION ON HUMAN RIGHTS INVOLVING TRADITIONAL PEOPLES}

\author{
${ }^{1}$ Isabela Feijó Sena Rodrigues \\ ${ }^{2}$ Cristina Figueiredo Terezo Ribeiro
}

\section{RESUMO}

O presente artigo objetiva analisar criticamente os casos da região amazônica envolvendo povos e comunidades tradicionais, admitidos pela Comissão Interamericana de Direitos Humanos contra o Brasil no período de 2005 a 2014, avaliando o litígio internacional a partir do perfil das violações de Direitos Humanos apresentadas nos casos e sua relação com as políticas de desenvolvimento territorial adotadas para a Amazônia.

Palavras-chave: Direitos Humanos; Comissão Interamericana de Direitos Humanos; Povos Tradicionais; Região Amazônica; Políticas de desenvolvimento

\begin{abstract}
This article aims to critically analyze the cases involving traditional peoples of the Amazon region, admitted by the Inter-American Commission on Human Rights against Brazil from 2005 to 2014, evaluating the international dispute from the profile of human rights violations presented in the cases and their relation to territorial development policies adopted for the Amazon.
\end{abstract}

Keywords: Human Rights; Inter-American Commission on Human Rights; Traditional Peoples; Amazon region; Development policies

\footnotetext{
${ }^{1}$ Mestranda e bolsista Capes em Direito pela Universidade Federal do Pará - UFPA, Pará (Brasil). Advogada Voluntária na Clínica de Direitos Humanos da Amazônia pela Universidade Federal do Pará - UFPA, Pará (Brasil). E-mail: isabela.feijo@ hotmail.com

${ }^{2}$ Doutora em Direito pela Universidade Federal do Pará - UFPA, Pará (Brasil). Coordenadora do Programa de Pós-Graduação em Direito pela Universidade Federal do Pará - UFPA, Pará (Brasil). E-mail: cfterezo@ hotmail.com
} 


\section{INTRODUÇÃO}

A região amazônica é marcada por violações históricas e estruturais de Direitos Humanos, na qual registram-se elevados índices de violência, conflitos e degradação ambiental que se desenvolvem em torno, principalmente, de questões territoriais, indicando que mesmo em tempos atuais, ainda se constata, no Brasil, cenários remanescentes da colonização.

A internacionalização dos Direitos Humanos, oriunda da necessidade de se construir uma sociedade internacional pautada pela proteção dos Direitos Humanos, face aos drásticos acontecimentos da II Guerra Mundial, ocasionou a reconfiguração da noção clássica de Direito Internacional, o qual deixa de estar concebido como objeto de interesse apenas dos Estados, tão somente para regular as relações interestatais, assumindo em sua nova concepção um caráter dinâmico, que produz impactos jurídicos e sociais em âmbitos domésticos, estimulando a atuação de diversos atores sociais.

Assim, projetado no domínio da Organização dos Estados Americanos (doravante OEA), o Sistema Interamericano de Direitos Humanos (doravante SIDH), composto pela Comissão Interamericana de Direitos Humanos (doravante CIDH ou Comissão) e pela Corte Interamericana de Direitos Humanos (doravante Corte IDH ou Corte), vem se constituindo, gradualmente, como um significativo instrumento para a proteção e garantia dos Direitos Humanos no Brasil, que se tornou signatário da Convenção Americana de Direitos Humanos (doravante CADH ou Convenção Americana) em 1992 e aceitou a jurisdição contenciosa da Corte IDH em 1998.

Contudo, em virtude da abrangência da competência da CIDH, que alcança não só os Estados-partes da CADH, mas todos os membros da Organização dos Estados Americanos, mediante a Carta da OEA e a Declaração Americana de Direitos e Deveres do Homem (doravante Declaração Americana), o órgão pronuncia-se em relação ao Brasil em casos que datam de 1970, sendo o referente aos índios Yanomami, em 1985, um dos mais notórios.

Destarte, a CIDH constitui-se como o meio pelo qual, os indivíduos ou as entidades da sociedade civil organizada, impulsionam o Sistema Interamericano, mediante a atribuição da mesma de receber e processar petições ou denúncias internacionais.

Diante de tal prerrogativa para o ingresso no SIDH, a Comissão é o órgão que está diretamente ligado à litigância internacional, o que, por sua vez, define o escopo do presente artigo, que se propõe a avaliar o litígio internacional a partir da análise crítica dos casos da 
região amazônica envolvendo povos tradicionais (entendendo-se como povos tradicionais, os povos indígenas e as comunidades quilombolas), que foram formalmente admitidos pela CIDH no período de 2005 a 2014 , sendo esta região considerada para o presente artigo a partir do conceito de Amazônia Legal, abarcando os Estados do Acre, Amapá, Amazonas, Mato Grosso, Pará, Rondônia, Roraima e Tocantins.

Nesse sentido, objetiva-se investigar o litígio internacional nestes casos no que diz respeito ao contexto amazônico que origina estas demandas, visando-se estabelecer uma relação entre as mesmas e as políticas de desenvolvimento territorial implementadas na Amazônia, adotando-se para o presente trabalho o referencial teórico que compreende a região amazônica como área de fronteira.

Para alcançar estes objetivos, a metodologia utilizada para este artigo foi a indutiva, uma vez que se partiu da análise de casos brasileiros individuais apresentados à CIDH, para após chegar-se a conclusões críticas sobre o perfil das violações de Direitos Humanos dos casos amazônicos, considerando também o método de análise histórico interpretativo para tanto.

Deste modo, levou-se em consideração a pesquisa bibliográfica, documental e jurisprudencial, consultando-se os autores que tratavam sobre o tema, instrumentos normativos, relatórios temáticos e jurisprudências do SIDH.

$\mathrm{Na}$ primeira parte do artigo, será abordado um panorama geral acerca do modo de ocupação da região amazônica, bem como as políticas de desenvolvimento implementadas para a mesma, buscando-se explicar o entendimento da Amazônia como área de expansão da fronteira, concebida como espaço estratégico, indicando-se as transformações territoriais, sociais e temporais oriundas das estratégias governamentais e empresariais para a região, que ocasionaram na manutenção de práticas coloniais e em violações de Direitos Humanos.

Outrossim, a segunda parte do artigo objetiva identificar as principais demandas desses casos amazônicos apresentadas à CIDH no período delimitado, de modo a analisar se há um perfil comum de violações de Direitos Humanos entre esses casos, fazendo-se um recorte especifico de análise dos casos envolvendo povos tradicionais, com o fim de apontar o reconhecimento limitado dos direitos desses povos, bem como a relação direta entre o modelo de ocupação e políticas de desenvolvimento adotadas na Amazônia e as graves violações de Direitos Humanos desses grupos que originam o peticionamento à Comissão Interamericana. 


\section{OCUPAÇÃO E POLÍticAS DE DESENVOLVIMENTO TERRITORIAL IMPLEMENTADAS NA AMAZÔNIA}

No Brasil, a história aponta que, desde a colonização, os grandes ocupantes das terras públicas têm se apropriado do solo e dos recursos naturais. Entretanto, não necessariamente, o atual ocupante é o primeiro que chegou, mas provavelmente é o que detém os recursos econômicos e, por essa razão, também o poder de manipular as leis e políticas públicas.

Nos tempos coloniais, a questão não era predominantemente territorial, visto que o escravo era quem representava o valor do patrimônio, enquanto que, atualmente, a ocupação territorial ganhou um sentido diverso, no qual os grandes proprietários e empresas vêm ocupando áreas que representam para estes e estas um território de conquista A ocupação do território se faz em razão da propriedade privada da terra, da relevância econômica da propriedade fundiária como fonte de renda e como instrumento para obtenção de incentivos fiscais e subsídios públicos (NOVAIS; SCHWARCZ, 1998).

O regime fundiário inserido pela Lei de Terras de 1850, salvo exceções, unificou domínio e posse para constituir o moderno regime de propriedade. Assim, a propriedade da terra e a renda fundiária passam a definir os modos de ocupação do país, da expansão de fronteiras econômicas e demográfica internas, da mentalidade que se estimula da possibilidade de tomar posse do território, de espoliar os povos indígenas e o posseiro, bem como de instituir a propriedade privada da terra (NOVAIS; SCHWARCZ, 1998).

Como reflexo dessas alterações e intervenções, na região amazônica observa-se um alarmante histórico de conflitos e violência no território, aliado a elevados índices de degradação ambiental, que se desenvolve em um contexto de um verdadeiro caos fundiário, em que conjugam-se concepções opostas sobre terra e território, público e privado, envolvendo agentes e grupos com interesses diversos e marcadamente antagônicos.

Nesse sentido, este cenário é resultado do modo como foi realizada a ocupação na Amazônia, sendo fundamental para esse entendimento a concepção da região como fronteira de expansão.

Desde os anos 50, o deslocamento da frente de expansão e a ocupação de terras de fronteira em locais como no Pará, por exemplo, podem ser vistos de um novo modo, mediante o mapa geográfico da violência, pela explosão dos conflitos fundiários que os acompanha, sendo esta a “versão moderna da Conquista (...), conflitos do 'branco' contra o índio, do branco contra o branco pobre, do branco pobre contra o índio, das modernas empresas contra os 
posseiros e indígenas e também contra peões escravizados" (NOVAIS; SCHWARCZ, 1998, p. 669).

Destaca-se ainda o período no qual a Amazônia foi drasticamente transformada em todos os aspectos pela política dita integracionista dos Governos Militares, iniciada na década de 60, marcada pela implantação dos Grandes Projetos, construção de rodovias federais, federalização de áreas, projetos de colonização, assentamentos e inserção do capital estrangeiro, além do registro do intenso movimento migratório para a região, intensificando a devastação ambiental, os conflitos rurais, a grilagem de terras (BENJAMIN et al., 2013.).

\begin{abstract}
Sob slogan "terra sem homens para homens sem terra" e sob a justificativa que de que a Amazônia constituía um "vazio demográfico", sua ocupação foi incentivada pelos militares. Em apenas 21 anos de Governo Militar, a ocupação da Amazônia foi maior que em cinco séculos de história. Uma série de projetos de colonização foi implantada de maneira desarticulada e desordenada (...) As políticas adotadas para Amazônia e para o Estado do Pará, em verdade, privilegiaram a entrada de grandes empresas nacionais e internacionais e o enfraquecimento do INCRA na década de 80 deixaramno à mercê de oligarquias locais, favorecendo a ampliação de latifúndios e concentração de renda (BENJAMIN et al., 2013.).
\end{abstract}

No contexto atual, Edna Castro (2012) afirma que a região amazônica ocupa lugar central na geopolítica brasileira, sendo que as estratégias empresariais e governamentais extrapolam suas fronteiras políticas, de modo que os Estados nacionais vizinhos da região amazônica também se movimentam economicamente na expansão da fronteira, a qual é concebida como um espaço estratégico e, segundo a autora, um campo aberto à produção de commodities, tendo em vista a sua vantagem competitiva de facilidade de escoamento para o mercado mundial.

Assim, a esfera política tem sido pressionada por atores globais, como as empresas transacionais, para que instituições e dispositivos legais sejam alterados a fim de atender às novas demandas e funcionamento da economia, a qual, sob a lógica liberalizante do capital, conduz os Estados a realizarem acordos com agências reguladoras internacionais, registrandose também a precarização das relações de trabalho (CASTRO, 2012).

Boaventura de Sousa Santos e Marilena Chaui (2013, p. 52) explicam esse fenômeno a partir do que chamam de "ilusão do antiestatismo", assinalando que:

\footnotetext{
"A promiscuidade crescente entre o poder político e o poder econômico, a hipertrofia das funções de acumulação do Estado em detrimento das funções de confiança e de hegemonia, as condicionalidades impostas por agências financeiras internacionais, o papel preponderante das empresas multinacionais na economia mundial, a concentração de riqueza, tudo isto tem contribuído para reorganizar o Estado, diluindo
} 
a sua soberania, submetendo-o à crescente influência dos poderosos atores econômicos nacionais e internacionais, fazendo com que os mandatos democráticos sejam subvertidos por mandatos de interesses minoritários, mas muito poderosos. Trata-se de uma transformação global que ocorre de modo desigual (graus e ritmos diferentes, fricção constante de contratendências) em diferentes regiões do mundo".

Logo, trata-se de um movimento rápido e simultâneo, em múltiplas direções, que se concretiza em um novo espaço de fluxos. No Brasil, há um reforço para que os projetos voltados para estados com grande faixa de fronteira, não somente em virtude de defesa territorial e segurança, mas também por questões de ordem econômica, ampliando-se a intervenção do Estado e o ordenamento dos espaços amazônicos, o que gera, principalmente, grandes impactos sociais e ambientais, constituindo-se como um projeto "amplo, totalizante, hegemônico e autoritário" (CASTRO, 2012, p. 50 -51).

Considerando esse cenário, verifica-se a associação entre as políticas nacionais brasileiras e os projetos de intervenção da Iniciativa para a Integração da Infraestrutura da América do Sul (IIRSA), bem como constata-se que os Planos de Aceleração do Crescimento (PAC I e II) e a IIRSA assumem a mesma orientação de integração competitiva, adotando um modelo de modernização baseado em megaprojetos de investimentos, articulados na concepção de eixos de integração e desenvolvimento (CASTRO, 2012), mantendo-se o espectro do “subimperialismo" brasileiro (SANTOS; CHAUI, 2013).

A IIRSA, bloco regional atuante no âmbito latino-americano e o PAC, bloco nacional, em âmbito nacional, são programas voltados para a logística de transporte, energia e comunicação, nos quais claramente pode se perceber uma reedição do modelo de desenvolvimento implementado na Amazônia nos anos 70, o qual provocou severos impactos sociais e ambientais (CASTRO, 2012).

A partir desta curta, mas reveladora, narrativa histórica e política da ocupação e das políticas de desenvolvimento territorial implementadas na região amazônica, é possível, em analogia com a classificação de Todorov, identificar nessas políticas desenvolvimentistas os grandes traços do "messianismo político": "programa generoso; divisão assimétrica dos papéis, ou seja sujeito ativo de um lado e, do outro, beneficiário passivo - cuja opinião não é pedida; recursos militares postos a serviço do projeto" (TODOROV, 2012, p. 47).

Com base nessa consideração, o que se analisa é que, muito embora as razões e interesses históricos se modificassem de acordo com o contexto amazônico da época, o projeto do sujeito ativo, seja ele o colonizador, os grandes proprietários, as empresas nacionais e transnacionais, ou os agentes governamentais, era e ainda é levado a cabo como algo superior, 
inquestionável e capaz de legitimar um objetivo elevado, a exemplo do "progresso", do “desenvolvimento", o qual assume diversos significados e justifica todos os meios empregados em prol da sua concretização, recriando ou aperfeiçoando processos de dominação, mediante a implantação de práticas que violam Direitos Humanos, como se observará no tópico seguinte.

\section{O PERFIL DAS VIOLAÇÕES DE DIREITOS HUMANOS NOS CASOS AMAZÔNICOS APRESENTADOS À COMISSÃO INTERAMERICANA DE DIREITOS HUMANOS}

A CIDH acompanha a consolidação dos Direitos Humanos no Brasil, desde seu estabelecimento em 1961, pronunciando-se em relação aos casos individuais e formulando importantes recomendações ao governo brasileiro. Em 1995, o governo brasileiro concedeu anuência à solicitação que a CIDH vinha fazendo desde 1989, para que fosse autorizada uma missão de observação in loco ao país, devido às situações preocupantes sobre violações de Direitos Humanos, de acordo com as informações oficiais, internacionais e de ONGs que estava recebendo (OEA, 1997).

Com efeito, de 27 de novembro a 19 de dezembro de 1995, os integrantes da CIDH realizaram a visita in loco no país, reunindo-se com membros do governo, da sociedade civil organizada, ouvindo depoimentos e coletando dados. Como resultado da missão, a CIDH elaborou o Relatório sobre a Situação dos Direitos Humanos no Brasil, publicado em 1997, o qual instituiu ao Brasil recomendações sobre as questões de Direitos Humanos analisadas, dentre as quais, destaca-se: os Direitos Humanos dos povos indígenas, a propriedade de terras rurais e os Direitos Humanos dos trabalhadores rurais (OEA, 1997).

À luz dos noves casos da região amazônica formalmente admitidos pela CIDH no período analisado, constatou-se que os mesmos permaneceram denunciando as mesmas violações elencadas no supramencionado Relatório da CIDH sobre o Brasil, comprovando o paradoxo da democratização e a permanência de violações de Direitos Humanos tão antigas, quanto atuais.

$\mathrm{Na}$ análise desses casos amazônicos, identificaram-se nove com as seguintes temáticas principais e correlatas: conflitos rurais; desrespeito aos territórios de povos indígenas e comunidades quilombolas; e crimes praticados contra defensores de Direitos Humanos, os quais na maioria dos casos defendiam os direitos dos trabalhadores rurais e lutavam pela regularização fundiária. 
Sob este prisma, é mister destacar que o processo de violação dos Direitos Humanos atinge principalmente os grupos sociais vulneráveis, como se verificou nessas demandas dos casos amazônicos, que apresentam como vítimas as comunidades indígenas e quilombolas, os trabalhadores rurais e os defensores de Direitos Humanos. Logo, nesse contexto, esses grupos exigem respostas diferenciadas e especificas, considerando-se as especificidades e peculiaridades de sua condição social (PIOVESAN, 2014).

No mesmo sentido, a Corte IDH (2012, par. 134) declara que:

(...) toda pessoa que se encontre em uma situação de vulnerabilidade é titular de uma proteção especial, em razão dos deveres especiais cujo cumprimento por parte do Estado é necessário para satisfazer as obrigações gerais de respeito e garantia dos direitos humanos. O Tribunal recorda que não basta que os Estados se abstenham de violar os direitos, sendo imperativa também a adoção de medidas positivas, determinadas em função das particulares necessidades de proteção do sujeito de direito, seja por sua condição pessoal ou pela situação específica em que se encontre (tradução nossa).

Em que pese a legislação brasileira tenha avançado na proteção e garantias de direitos, esses avanços não têm sido devidamente reconhecidos/concretizados no plano judicial e nem contemplados nas práticas estatais, permanecendo o Estado como o principal violador desses direitos, como será demonstrado a seguir nos casos da região amazônica envolvendo povos tradicionais, em que o modelo de ocupação e as políticas de desenvolvimento aplicadas para a região, foram determinantes para a ocorrência das violações de Direitos Humanos, ensejando conflitos fundiários e socioambientais.

\section{1 CASOS ENVOLVENDO POVOS TRADICIONAIS}

A região amazônica é marcada pelos altos índices de violência, degradação ambiental e exclusão social em seu espaço geográfico, o qual é palco de complexos conflitos históricos e estruturais que envolvem diversos atores sociais, como os povos indígenas e as comunidades quilombolas, os quais ainda não são vistos de fato pelo Estado, como sujeitos de direitos, apesar da Constituição Federal de 1988 consagrar dispositivos que representaram avanços no reconhecimento da plurietnicidade e dos direito territoriais desses povos tradicionais.

Acerca desse reconhecimento dos direitos dos povos indígenas, os anos 70 e 80 foram marcados pelos manifestos, testemunhos e abaixo-assinados como meios de protesto e denúncia para chamar a atenção das autoridades internacionais, uma vez que tentativas internas nos países, particularmente do Cone Sul, não surtiriam efeitos (BELTRÃO et al., 2014). 
Nesse período, como acima exposto, registrava-se no Brasil, os projetos integracionistas implementados pelos governos militares na Amazônia, com o objetivo de "preencher vazios demográficos", a partir de grandes obras e empreendimentos de infraestrutura e migrações populacionais.

De tal modo, os acontecimentos ocorridos proporcionaram o crescimento dos movimentos indígenas na América Latina e permitiram "a luta pela ins/constituição cidadã dos povos indígenas que implica na inscrição de marcadores sociais da diferença como conceitos jurídicos impressos na legislação", especialmente no plano constitucional, revelando assim, maneiras de produzir e apresentar o discurso sobre a diversidade cultural, estabelecendo as condições de possibilidade para utilização dos direitos para a emancipação (durante a ditadura, o Brasil pretendeu "emancipar" os povos indígenas a sua revelia, para de desvencilhar das obrigações relacionadas à diversidade) ou violação (direitos étnicos) aos povos indígenas (BELTRÃO et al., 2014).

Ademais, ressalta-se que as reformas estatais da maioria dos Estados da América Latina tiveram como aspecto fundamental para a sua concretização os instrumentos de proteção internacional dos Direitos Humanos, como a Convenção 169 da Organização Internacional do Trabalho - OIT (que reconheceu direitos coletivos de caráter político, incluindo direitos de participação no Estado), amplamente ratificada, e a Declaração das Nações Unidas sobre os Direitos dos Povos Indígenas (em matéria de direitos políticos, reconheceu o direito à livre determinação, à autonomia e ao autogoverno, entre outros) (BELTRÃO et al., 2014).

Tal conjuntura social latino-americana, o papel ativo dos movimentos indígenas e indigenistas e a adoção de instrumentos internacionais de Direitos Humanos, marcaram a evolução dos trabalhos da CIDH e a consolidação de estudos especializados que, desde 1991, fixaram as bases para os trabalhos da Corte IDH (BELTRÃO et al., 2014), observando-se que em junho do presente ano, após quase 30 anos, a OEA adotou a Declaração Americana sobre os Direitos dos Povos Indígenas.

A jurisprudência da Corte IDH tem contribuído sobremaneira na proteção dos Direitos Humanos dos povos indígenas, particularmente no que se refere aos direitos políticos, ao reconhecer o direito dos indígenas de participar, em condições de igualdade, na tomada de decisões em assuntos políticos, integrando-se nos órgãos estatais de forma proporcional com a sua população, bem como em matéria dos direitos sobre a terra e os recursos naturais, ao dispor sobre a propriedade ancestral comunal destes povos sobre essas terras, como declarou no caso Awas Tingni vs. Nicarágua de 2001, dentre outros (BELTRÃO et al., 2014). 
Entretanto, muito embora esses avanços sejam relevantes, os mesmos não foram sempre acompanhados de uma legislação que permitisse cumpri-los, assim como de políticas públicas efetivas que assegurassem os direitos dos povos indígenas (BELTRÃO et al., 2014), de modo que as lacunas de implementação persistem, comprometendo a efetividade desses direitos.

No que tange aos direitos territoriais, a situação do Brasil apresenta conquistas e entraves: tem se impulsionado processos demarcatórios de terras indígenas significativos, contudo, muitas dessas terras, continuam sendo objeto de invasões por diversos grupos como posseiros, madeireiros, garimpeiros, empresas nacionais e transnacionais, entre outros. Este contexto afeta gravemente a muitos povos indígenas, sendo que muitos dos projetos desenvolvimentistas implementados são apoiados e financiados pelo governo federal e inseridos dentro do PAC (BELTRÃO et al., 2014).

Outro tema crítico, é que a propriedade das terras não pertence aos povos indígenas, mas à União, o que consiste em uma das principais matérias do Brasil que chegam à CIDH, mediante as petições individuais.

As comunidades indígenas e quilombolas possuem seus territórios como objeto dos conflitos fundiários e do caos fundiário como um todo (SAUER; ALMEIDA, 2011) não lhes sendo garantido o seu direito legítimo a esses territórios, como demonstrou-se nos casos das Comunidades Indígenas de Ananás, caso n. 62-02 (OEA, 2006a), de Raposa Serra do Sol, caso n. ${ }^{\circ}$ 250-04 (OEA, 2010), bem como no caso da Comunidade Quilombola de Alcântara, caso n. ${ }^{\circ}$ 555-01 (OEA, 2006b).

O caso da comunidade indígena de Ananás aborda a questão conflituosa que tem se estabelecido na terra indígena de Ananás, a qual encontra-se situada na região de Amajari, ao noroeste da cidade de Boa Vista, Roraima.

O processo de demarcação de terras, iniciado em 1980, não observou o laudo antropológico em virtude de forte pressão e atos intimidatórios, atribuindo assim, território bem menor do que efetivamente teria direito o referido povo indígena. Após sucessivos conflitos entre indígenas e fazendeiros nesse período e que se mantiveram até o ano do relatório, em 2006, verificou-se que, o número de famílias Macuxi identificadas na terra teve uma expressiva diminuição, vez que muitos, inclusive, abandonaram suas terras por serem impedidos de ter acesso a serviços públicos básicos por fazendeiros e intimidados por emboscadas.

A FUNAI tomou conhecimento dos fatos, mas não tomou medidas frente aos mesmos, permanecendo o caso sem solução. Em relação à emboscada, abriu-se um inquérito policial, mas a investigação não obteve resultado. O Ministério Público não instaurou ação penal contra 
os agressores e ação civil impetrada ainda se encontra pendente de resolução. O Estado brasileiro tampouco apresentou contestação, mostrando total descaso com a acusação.

Semelhantemente, o caso do povo da Raposa Serra do Sol, em Roraima, versa sobre um atraso que data de 1977 a 2009 para a consumação efetiva da demarcação, delimitação e titulação do território indígena da Raposa Serra do Sol, assim como frequentes incidentes violentos e severa degradação ambiental que têm sido causados pela contínua presença de pessoas não indígenas dentro desse território, o que também produz restrições ao direito de circulação e residência, liberdade de religião e direito a exercer sua cultura.

Os peticionários do caso alegaram que houve atraso injustificado na resolução do processo administrativo de demarcação do território indígena e que inexistem disposições na legislação do Estado que garantam o devido processo legal, a proteção dos direitos territoriais e a igualdade perante a lei dos povos indígenas, pois não é garantido aos povos indígenas o direito à propriedade (que seria da União), sendo apenas garantida a posse de suas terras.

Portanto, o reconhecimento desses direitos encontra sérios entraves, resistência legal e ilegal dos interesses econômicos envolvidos na cobiça de terras indígenas, bem como o sistema judicial conservador, pouco sensível a direitos coletivos e justiça histórica, parcela de governantes que não enxergam os povos indígenas para além de seu peso eleitoral mínimo, e a discriminação racial anti-indígena e antinegra (SANTOS; CHAUI, 2013).

Se questiona, assim, o lugar discursivo e disciplinar de onde as questões jurídicas e políticas são estratégicas e institucionalmente colocadas de forma a representar a alteridade da "identidade nacional" e a partir do qual fomentam espaços de "contradição" e "confrontação" (BELTRÃO et al., 2014, p. 265).

Por contradição, segundo os autores Jane Felipe Beltrão e Assis da Costa Oliveira, entende-se a ambiguidade e a polifonia ideológica da consagração normativo-constitucional da alteridade dos povos indígenas. As constituições analisadas pelos autores apresentam, segundo os mesmos, restrições ao reconhecimento integral da diversidade cultural, seja pelo controle por instituições públicas, seja por não igualarem o status das culturas diferenciadas ao da cultura "nacional" (BELTRÃO et al., 2014).

A confrontação, por sua vez, representa os efeitos da aplicabilidade concreta - em decisões judiciais, políticas públicas e relações sociais - da tensão sociocultural e ideológica da presença de povos indígenas como sujeitos coletivos diferenciados inseridos em sociedades democráticas e pós coloniais, nas quais a diversidade ainda é, via de regra, pensada como desigualdade. A sua principal consequência é a criminalização das práticas judiciais dos povos 
indígenas, o que é também o enfoque colonial e moderno da exclusividade estatal da função jurisdicional que penaliza procedimentos indígenas (BELTRÃO et al., 2014).

O contexto político atual, apresenta o modelo extrativista e agroindustrial que intensifica a expansão por terras e territórios e é composto por instrumentos jurídicos de asfixia dos povos tradicionais, a exemplo do novo Código Florestal, da Proposta de Emenda à Constituição (PEC) 215, que versa sobre a transferência do Executivo para o Congresso Nacional do poder de decidir sobre demarcação de terras indígenas e quilombolas, e da Portaria n. 303, que está suspensa, mas pode entrar em vigor, e diz respeito à restrição do usufruto das comunidades sobre os seus territórios (SANTOS; CHAUI, 2013).

Por essa portaria, é possível prever a inviabilização de novas demarcações de terra, além da revisão de territórios indígenas já demarcados e homologados para se adequarem a nova normativa, além da previsão da permissão de não consultar os povos indígenas para a instalação em terras indígenas de bases, unidades, hidrelétricas e demais obras, abrindo-se ainda mais o caminho para o agronegócio e projetos de infraestrutura.

Sobre esse assunto, o caso da Comunidade Quilombola de Alcântara, localizada no Maranhão, demonstra peculiaridade em relação aos demais admitidos pela CIDH, embora também possua como eixo central violações do direito à propriedade, posto que versa acerca das consequências da expropriação desordenada promovida pelo Estado para a criação da Base Espacial "Centro de Lançamento de Alcântara (CLA)", o que gerou desestruturação sociocultural das comunidades nativas daquela região, muitas delas quilombolas.

O caso indica que há também outras comunidades, que mesmo fora dessa região, estão sofrendo prejuízos indiretos, no que diz respeito a aspectos econômicos, familiares, culturais e religiosos ocasionados pelos diversos efeitos causados pelo empreendimento supracitado.

Assim, as políticas de desenvolvimento predatório adotadas pelo Estado, desconsideram a sociodiversidade e o meio ambiente e, por conseguinte, violam os direitos desses povos tradicionais.

Essa reconfiguração do território, conforme abordado, aconteceu a partir de mudanças no sistema de produção capitalista, que tenderam a comprimir espaço e tempo e a adotar uma lógica de deslocalização. O território é importante dentro de uma outra perspectiva, a qual é desconectada de valores, lugares, tradições e passa a ser regido por relações econômicas e políticas, protagonizadas, principalmente, por agentes do mercado (CASTRO, 2012).

Tal rompimento com as raízes, as heranças culturais e com as territorialidades, torna-se um desafio para as empresas, corporações e também para o Estado, uma vez que suas políticas 
priorizam o mercado, em contrariedade aos interesses locais, como os dos grupos que vivem na Amazônia, os quais se estabelecem a partir de outras concepções de território e territorialidade, regidos por outra ordem social de espaço e tempo, e não necessariamente pelo mercado (CASTRO, 2012).

Destarte, estão em jogo grandes interesses de empresas, bancos, agencias nacionais e internacionais, e aportes financeiros públicos e privados com capacidade de impor seus interesses no espaço e tempo. Por isso, levanta-se a hipótese de que estamos diante de um grande investimento governamental que tende a provocar transformações para além da fronteira nacional (CASTRO, 2012).

Este modelo de desenvolvimento se constitui pela voracidade no que tange à expansão de terras e territórios, o que transforma os povos tradicionais em obstáculos ao desenvolvimento (SANTOS; CHAUI, 2013), indicando o chamado potencial emancipatório limitado ou desconsiderado da cidadania, face aos dilemas políticos, jurídicos, econômicos e sociais que se posicionam mais perto do neocolonialismo do que do pós-colonialismo (BELTRÃO et al., 2014).

Logo, o centro do debate é a não superação concreta da hierarquização entre nacionalidade e etnicidade frente à permanência da noção de cidadania liberal, assentada na vinculação ao estado-nação a partir do compartilhamento de valores comuns da democracia liberal, o que se revela em uma representação imaginária, com temporalidade e “terroritorialização" sob o comando exclusivo do poder central estatal (BELTRÃO et al., 2014).

Portanto, há o conflito permanente entre direitos individuais e coletivos; soberania política estatal e autonomia dos povos indígenas; e graus assimétricos de reconhecimento normativo dos marcadores sociais da diferença em especial àqueles constituintes da livre determinação dos povos indígena (BELTRÃO et al., 2014).

Resta claro, então, que nas frentes de expansão, como é encarada a região amazônica, está-se diante de uma "ilegalidade fundante" estruturante (NOVAIS; SCHWARCZ, 1998, p. 667), que é a lei imposta em favor de alguns, os grupos políticos e economicamente vinculantes, mediante violação de costumes e de direitos legítimos e outros, existindo nessas persistências muita coisa parecida com os cenários do passado: "paisagens, fugas, medos, linguagem, lendas, histórias, mentalidades, classificações e diferenciações de coisas e pessoas" (NOVAIS; SCHWARCZ, 1998, p. 664).

Evidencia-se no presente, um passado "nunca resgatado nem superado de confiscos, expulsões, violências" (SANTOS; CHAUI, 2013, p. 105), no qual, muito embora os contextos 
históricos se modifiquem, a linguagem retórica que legitima o direito de intervir, prossegue a partir de novas justificativas, conceitos e significados, adequados às circunstâncias fáticas, mas que carregam a mesma matriz da argumentação dos embates de tempos coloniais, semelhantes aos ocorridos no séc. XVI, na Espanha, entre Bartolomé de las Casas e Juan Sepúlveda, em que discutia-se "quem tem o direito de intervir, quando e como?", em relação ao direito dos conquistadores espanhóis contra os povos indígenas da região americana (WALLERSTEIN, 2007).

Em tempos atuais, considerando a ocupação e as políticas integracionistas e desenvolvimentistas voltadas para a Amazônia, questiona-se: Para quem ou à quem servirá a integração e o "desenvolvimento"?

Certamente, a resposta não é simples e toca em pontos sensíveis, como a lógica do capital, a tendência histórica de exclusão, a reconfiguração do tempo e do espaço, as demandas econômicas e sociais, as políticas públicas e especialmente em danos incapazes de serem reparados e muito menos, mitigados, como a perda de elementos culturais e ancestrais das culturas e costumes dos povos tradicionais.

Para se discutir essa problematização, é fundamental que a cidadania seja pensada de forma plural, visto que que nem sempre a sua noção inclui o reconhecimento do direito de diferenciação legítimo que efetive a igualdade de condições que permita aos povos indígenas e as comunidades quilombolas serem cidadãos plenos mas "sem deixar de ser membro igualmente pleno de suas respectivas sociedades" (BELTRÃO et al., 2014, p. 255).

\section{CONCLUSÃO}

A Amazônia, mediante os seus processos de ocupação, integração e desenvolvimento, tem se tornado um espaço de repercussão das dinâmicas sociais, da intervenção de megaprojetos, os quais desestruturam determinadas ordem sociais e ambientais existentes, e disponibilizam novas fronteiras de terra para expansão exploração de recursos naturais, mantendo o histórico antigo da região como produtora de commodities.

O Estado brasileiro, por sua vez, opta pela concepção mais conservadora e nociva de desenvolvimento, que vai na contramão da tríade ambiental que reúne os aspectos econômicos, sociais e ambientais, bem como o respeito aos padrões internacionais de proteção aos Direitos Humanos, de modo que essa política desenvolvimentista tem se revelado ineficaz social e ambientalmente, aplicando projetos de construção de grandes obras de infraestrutura e 
utilizando argumentos que supervalorizam os benefícios do desenvolvimento, com obras localizadas no território brasileiro e nas áreas amazônicas de países vizinhos, mediante políticas como a da IIRSA.

O Sistema Interamericano de Proteção dos Direitos Humanos, como um sistema de proteção regional, apresenta como o seu diferencial, a proximidade com aqueles que o compõem e logo, com a realidade social, econômica e cultural, em quem estão inseridos, uma vez que busca analisar não somente os casos isolados, mas sim o contexto no qual se desenvolvem e adquirem sentido, visando acompanhar as mudanças que ocorrem na sociedade, de modo que a interpretação de seus instrumentos de proteção dos Direitos Humanos mantenhase em constante evolução, para adequar-se às demandas contemporâneas e proporcionar a resposta mais benéfica ao indivíduo.

Ao longo do tempo, a CIDH veio se fortalecendo e se constituindo não só como o órgão principal da OEA, mas também como órgão principal do Sistema Interamericano, diante das múltiplas funções que desempenha para promover a observância e a proteção dos Direitos Humanos, auxiliando na publicidade das violações aos mesmos, o que, por sua vez, pode acarretar em um constrangimento político e moral ao Estado denunciado, e mais ainda: gerar impacto transformador na política de Direitos Humanos e na legislação em âmbito interno dos países.

Ademais, em razão de uma de suas funções mais importantes, que é o recebimento de denúncias internacionais alegando violações de Direitos Humanos, a Comissão é responsável por viabilizar o acesso dos indivíduos ao SIDH, o que a torna um legítimo fórum de discussão da sociedade civil acerca de temáticas dos referidos direitos.

Nesse sentido, a avaliação dos casos amazônicos admitidos permitiu também que se traçasse um perfil das principais violações de Direitos Humanos denunciadas, em que se percebeu que a forma de ocupação e a política de desenvolvimento implementada para região priorizam interesses econômicos e políticos, o que atingiu e atinge diretamente os grupos vulneráveis, como as povos indígenas e as comunidades quilombolas, os quais tem uma história de luta pelo reconhecimento dos seus direitos coletivos, que, apesar de consagrados no texto constitucional, estão sempre enfrentando resistências e risco de serem revertidos, em virtude de pressões econômicas, políticas ou sociais.

Ademais, os avanços constitucionais e jurídicos, apesar de significativos, apresentam limites e desafios na sua implementação, de modo que ainda há uma clara distância entre o reconhecimento formal e a participação e autonomia de fato desses povos tradicionais. 
O resultado deste cenário é um espaço de proliferação de graves violações de Direitos Humanos, caracterizado pela ação ou omissão violadora do Estado, mediante a ausência ou deficiência de instrumentos jurídicos para prevenir ou reparar esses direitos e a conivência entre os órgãos estatais e os grupos influentes da região, criando-se assim condições propícias para impunidade dos responsáveis e intensificação da vulnerabilidade dos grupos sociais, o que se reflete então, nos índices alarmantes de violência e degradação ambiental.

Sobre este aspecto, convém destacar que a litigância internacional para ser verdadeiramente estratégica, deve levar em consideração todas essas peculiaridades que caracterizam os casos amazônicos, e compreender que, em muitos casos, a solução meramente legal ou jurídica será insuficiente para resolver violações complexas e históricas que tem suas raízes na forma de ocupação e desenvolvimento da Amazônia.

Por fim, insta ressaltar que o Estado brasileiro, além de não solucionar estas violações em âmbito interno, demonstrou pouco ou nenhum interesse em justificar ou tentar resolver as controvérsias levadas à CIDH referentes aos casos envolvendo povos tradicionais da região amazônica, o que compromete a eficácia da proteção internacional e evidencia o desrespeito do Brasil com o seu compromisso de proteger e garantir os Direitos Humanos, bem como de disponibilizar recursos efetivos e adequados para solucionar as violações destes direitos.

\section{REFERÊNCIAS}

BELTRÃO Jane Felipe; BRITO FILHO, Jose Claudio Monteiro de; GÓMEZ, Itziar; PAJARES, Emilio; PAREDES, Felipe; ZÚÑIGA, Yanira (Coords.). Derechos humanos de los grupos vulnerables, 2014. Disponível em: http://www.upf.edu/dhes-alfa/materiales/. Acesso em: 20 jun. 2016.

BENJAMIN, Antonio Herman et al. (Org.). Licenciamento Ética e Sustentabilidade. São Paulo: $18^{\circ}$ Congresso Brasileiro de Direito Ambiental, 2013. Disponível em: http://www.planetaverde.org/arquivos/biblioteca/arquivo_20131201045021_6976.pdf. Acesso em: 10 jun. 2016.

CASTRO, Edna. Expansão da Fronteira, megaprojetos de infraestrutura e integração sulamericana. Caderno CRH, v. 25, n. 64, p. 45-61, 2012.

CORTE INTERAMERICANA DE DIREITOS HUMANOS (CORTE IDH). Caso Furlan e Familiares vs. Argentina. Sentença de exceções preliminares, mérito, reparações e custas, de 31 de agosto de 2012. Disponível em: http://www.corteidh.or.cr/. Acesso em: 10 jun. 2016. 
MARTINS, José de Souza. A vida privada nas áreas de expansão da sociedade brasileira. In: NOVAIS, Fernando A; SCHWARCZ, Lilia Moritz. (Orgs). História da vida privada no Brasil. vol 4. São Paulo: Companhia das Letras, 1998.

ORGANIZAÇÃO DOS ESTADOS AMERICANOS (OEA). Comissão Interamericana de Direitos Humanos. Relatório Sobre a Situação dos Direitos Humanos no Brasil. 1997. Disponível em: http://www.oas.org/pt/cidh/. Acesso em: 10 jun. 2016.

ORGANIZAÇÃO DOS ESTADOS AMERICANOS (OEAa). Comissão Interamericana de Direitos Humanos. Caso n. ${ }^{\circ}$ 62-02, relatório de admissibilidade n. ${ }^{\circ}$ 80/06. 2006. Disponível em: http://www.oas.org/pt/cidh/. Acesso em: 10 jun. 2016.

ORGANIZAÇÃO DOS ESTADOS AMERICANOS (OEAb). Comissão Interamericana de Direitos Humanos. Caso n. ${ }^{\circ}$ 555-01, relatório de admissibilidade n. ${ }^{\circ}$ 82/06. 2006. Disponível em: http://www.oas.org/pt/cidh/. Acesso em: 10 jun. 2016.

ORGANIZAÇÃO DOS ESTADOS AMERICANOS (OEA). Comissão Interamericana de Direitos Humanos. Caso n. ${ }^{\circ}$ 250-04, relatório de admissibilidade n. ${ }^{\circ}$ 125/10. 2010. Disponível em: http://www.oas.org/pt/cidh/. Acesso em: 10 jun. 2016.

PIOVESAN, Flávia. Direitos humanos e justiça internacional: um estudo comparativo dos sistemas regionais europeu, interamericano e africano. 5. ed. São Paulo: Saraiva, 2014.

SANTOS, Boaventura de Sousa; CHAUI, Marilena. Direitos humanos, democracia e desenvolvimento. São Paulo: Cortez, 2013.

SAUER, Sérgio; ALMEIDA, Wellington (Org.). Terras e territórios na Amazônia: demandas, desafios e perspectivas. Brasília: UnB, 2011.

TODOROV, Tzvetan. Os inimigos íntimos da democracia. São Paulo: Companhia das Letras, 2012.

WALLERSTEIN, Immanuel. O universalismo europeu. São Paulo: Boitempo, 2007. 